\title{
Calcipotriol/Betamethasone Dipropionate Cutaneous Foam Treatment for Psoriasis in Patients With BSA 5-15\% and PGA $\geq 3$ : Post-Hoc Analysis From Three Randomized Controlled Trials
}

Lars Iversen · Merle Kurvits · Anja Marieke Snel-Prentø · Alan Menter

Received: May 15, 2020 / Published online: August 12, 2020

(C) The Author(s) 2020

\section{ABSTRACT}

Introduction: Psoriasis is a chronic, inflammatory disease, which ranges in severity from mild to severe. Although topical therapies are frequently used to treat mild disease, they are not routinely used to treat patients with moderateto-severe disease who have a larger proportion of their body surface area (BSA) affected ( $\geq 5 \%$ BSA). Based on well-controlled trials in adults with mild-to-severe disease, fixed-dose combination calcipotriol $50 \mu \mathrm{g} / \mathrm{g}+$ betamethasone dipropionate $0.5 \mathrm{mg} / \mathrm{g}$ (Cal/BD) cutaneous foam has been approved (Enstilar ${ }^{\circledR}$, LEO Pharma) in the USA and EU for the treatment of psoriasis vulgaris for up to 4 weeks in adults. In

Digital Features To view digital features for this article go to: https://doi.org/10.6084/m9.figshare.12554747.

L. Iversen $(\bowtie)$

Department of Dermatology, Aarhus University

Hospital, Aarhus, Denmark

e-mail: lars.iversen@clin.au.dk

M. Kurvits

Biostatistics Department, LEO Pharma, Ballerup, Denmark

A. M. Snel-Prentø

Global Medical Affairs, LEO Pharma, Ballerup,

Denmark

A. Menter

Division of Dermatology, Baylor Scott \& White

Health, Dallas, TX, USA this post-hoc subgroup analysis, we used pooled data from phase II/III trials to investigate the efficacy and safety of Cal/BD cutaneous foam in patients with moderate-to-severe psoriasis.

Methods: Patients included in this analysis had psoriasis affecting 5-15\% BSA and a physician's global assessment $(\mathrm{PGA}) \geq 3$. Endpoints included: treatment success by PGA (rating: clear/almost clear), patient's global assessment (PaGA) at week 4 (rating: clear/very mild) and safety.

Results: A total of 340 patients in the three randomized trials met the BSA/PGA inclusion criteria, of whom 254 were treated with Cal/BD foam and 86 with vehicle foam. Treatment success by PGA and PaGA at week 4 was achieved in 143 (58.1\%) and 138 (56.1\%) patients receiving $\mathrm{Cal} / \mathrm{BD}$ foam, respectively, versus three $(3.6 \%)$ and $14(16.7 \%)$ patients receiving vehicle foam. Sixty-six adverse events (AEs) occurred in $47(18.5 \%)$ patients receiving Cal/BD foam and 11 AEs occurred in $11(12.8 \%)$ patients receiving vehicle foam. Three severe AEs and 15 non-serious treatment-related AEs occurred in patients receiving Cal/BD foam.

Conclusion: The results from three clinical trials analyzed together show that topical Cal/BD foam is well tolerated and efficacious for treating patients with moderate-to-severe disease. Data support Cal/BD foam as a potential topical therapy for moderate-to-severe psoriasis.

Trial registrations: ClinicalTrials.gov registration numbers: NCT01866163, NCT02132936, NCT01536886. 
Keywords: Betamethasone

dipropionate;

BSA $\geq 5 \%$; Calcipotriol; Enstilar; Foam; Moderate-to-severe; $\quad$ PGA $\geq 3$; $\quad$ Post-hoc; Psoriasis; Topical application

\section{Key Summary Points}

Topical therapies are not routinely used to treat patients with moderate-to-severe psoriasis despite approval for use in patients with mild-to-severe psoriasis.

The aim of this post-hoc subgroup analysis of three clinical trials was to provide data on the efficacy and safety of fixed-dose combination calcipotriol $50 \mu \mathrm{g} / \mathrm{g}$ plus betamethasone dipropionate $0.5 \mathrm{mg} / \mathrm{g}$ (Cal/BD) cutaneous foam in patients with moderate-to-severe psoriasis.

Treatment success as assessed by physician's global assessment and patient's global assessment at week 4 was achieved in 58.1 and $56.1 \%$ patients receiving $\mathrm{Cal} / \mathrm{BD}$ foam, respectively, versus 3.6 and $16.7 \%$ patients receiving vehicle foam.

The data support Cal/BD foam as a potential topical therapy for moderate-tosevere psoriasis

\section{INTRODUCTION}

Psoriasis vulgaris is a chronic, inflammatory, multifactorial disease with skin and joint manifestations [1] and is associated with multiple comorbidities and clinical features, including psoriatic arthritis, metabolic syndrome, cardiovascular disease, hepatic steatosis and increased spleen volume $[2,3]$. Psoriasis ranges in severity from mild to severe, with varying proportions of body surface area (BSA) being affected [4]. Among adults, psoriasis is typically mild, defined as affecting $<5 \%$ BSA, and is treated with topical therapies $[1,4]$. Patients with moderate-to-severe disease have a larger proportion of BSA affected ( $\geq 5 \%$ ) [4] and are treated with systemic and biologic therapies [5]. Many topical therapies are approved to treat patients with moderate-to-severe psoriasis, although these are predominantly used to treat mild disease [1].

To improve upon the cosmetic properties and established efficacy profile of fixed-dose combination calcipotriol $(50 \mu \mathrm{g} / \mathrm{g}$; as monohydrate; Cal) plus betamethasone $(0.5 \mathrm{mg} / \mathrm{g}$; as dipropionate; $\mathrm{BD}$ ) ointment and gel formulations, a foam formulation was developed. When applied, Cal/BD foam forms a stable, supersaturated solution on the skin, leading to increased skin penetration and local bioavailability of both components, compared with other formulations [6]. The topical, fixed-dose combination of $\mathrm{Cal} / \mathrm{BD}$ foam is currently approved in the USA (in adults and adolescents) and EU (in adults) for the treatment of plaque psoriasis $[7,8]$. The efficacy and safety of Cal/BD foam in adult patients with mild-to-severe psoriasis have been evaluated in several clinical trials. In three randomized controlled trials (NCT01866163 [9], NCT02132936 [10], NCT01536886 [11]), treatment with Cal/BD demonstrated superior efficacy over the comparators after 4 weeks of treatment.

Clinical case reports and non-interventional studies indicate that Cal/BD foam can also be used to treat patients with moderate-to-severe psoriasis [12]. In a real-world study in Germany, $43 \%$ of patients with severe psoriasis achieved treatment success after 4 weeks of once-daily $\mathrm{Cal} / \mathrm{BD}$ foam, as assessed by investigator's global assessment (IGA); adverse events (AEs) were reported in a minority of patients (7\%) [13]. Similarly, results from a real-world, 4-week, prospective study evaluating $\mathrm{Cal} / \mathrm{BD}$ foam in adult patients with moderate-to-severe plaque psoriasis and involvement of the palmar area demonstrated an improvement in assessments of disease severity and cutaneous pain associated with skin lesions [14].

This post-hoc subgroup analysis was undertaken to determine the efficacy and safety of $\mathrm{Cal} / \mathrm{BD}$ foam in patients with psoriasis vulgaris with 5-15\% BSA and a physician's global assessment (PGA) of $\geq 3$, in a pooled dataset from the three randomized trials listed above. 
The post-hoc analysis will better aid clinical decisions on the use of topical therapy in patients with moderate-to-severe disease, a population for which it is not routinely used.

\section{METHODS}

\section{Trial Design}

This was a post-hoc subgroup analysis in patients with psoriasis affecting 5-15\% BSA and a $P G A \geq 3$. Data were pooled from one phase II and two phase III trials (NCT01536886, NCT01866163, NCT02132936), which evaluated the efficacy and safety of Cal/BD foam versus foam vehicle in adult patients with mildto-severe psoriasis vulgaris ( 2 of the pooled trials also included evaluation of $\mathrm{Cal} / \mathrm{BD}$ gel and $\mathrm{Cal} /$ BD ointment, respectively). Detailed methods for each individual trial, including protocol approvals, registration and patient consents, are published elsewhere [9-11].

Approval was obtained from all relevant Institutional Review Boards and/or Independent Ethics Committees and Regulatory Authorities prior to the enrollment of patients. All patients provided written informed consent. The trials were conducted in accordance with the Declaration of Helsinki 1964, as revised 2013, concerning human and animal rights, Good Clinical Practice and Ethical Principles for Medical Research Involving Human Subjects.

\section{Interventions}

Patients were treated with the once-daily, fixeddose combination of Cal/BD foam (Cal $50 \mu \mathrm{g} / \mathrm{g}$; $\mathrm{BD}, 0.5 \mathrm{mg} / \mathrm{g}$ ) or foam vehicle for up to 4 weeks in two of the trials and up to 12 weeks in the third trial. For reporting consistency, this pooled analysis included the trial data collected up to week 4 .

\section{Endpoints}

The primary efficacy endpoint was treatment success at week 4 by PGA (defined as clear/almost clear [10] according to the 5-point PGA scale of clear, almost clear, mild, moderate and severe). Treatment success by PGA was also assessed at week 1 and week 2 . Other efficacy endpoints included: treatment success by patient's global assessment (PaGA; defined as clear/very mild); itch score (by visual analog scale, 0-100); modified Psoriasis Area and Severity Index (mPASI; excluding the head); and PASI75 (at least 75\% reduction in mPASI from baseline) at week 4 . The weekly amount of product used during the total treatment period and safety AEs were monitored throughout.

\section{Statistical Analysis}

Between-group differences (Cal/BD foam vs. foam vehicle) were analyzed using a Cochran-Mantel-Haenszel test adjusted for the original trial, and analysis of covariance adjusted for the original trial and baseline score. SAS version 9.4 statistical software (SAS Institute, Cary, NC, USA) was used during the analysis.

\section{RESULTS}

\section{Demographics and Baseline Characteristics}

The overall pooled population included 848 randomized patients, of whom 340 (40.1\%) had psoriasis affecting $5-15 \%$ BSA and PGA $\geq 3$ and were therefore included in the post-hoc analysis. Of these 340 patients, 254 (74.7\%) received Cal/BD foam, and 86 (25.3\%) received foam vehicle. Of those included in the post-hoc analysis 325 (95.6\%) completed the trials: 244 $(96.1 \%)$ in the Cal/BD foam group and 81 $(94.2 \%)$ in the foam vehicle group.

Baseline characteristics are listed in Table 1. Median BSA affected by psoriasis at baseline was $7.0 \%$ for both treatment groups. At baseline, $230(90.6 \%)$ and $78(90.7 \%)$ patients had moderate psoriasis by PGA in the $\mathrm{Cal} / \mathrm{BD}$ and vehicle foam groups, respectively. 
Table 1 Baseline characteristics of patients according to treatment group

\begin{tabular}{|c|c|c|}
\hline Baseline characteristic & Cal/BD foam $(n=254)$ & Foam vehicle $(n=86)$ \\
\hline Age (years), mean (SD) & $52.4(13.7)$ & $47.9(14.3)$ \\
\hline \multicolumn{3}{|l|}{ Sex, $n(\%)$} \\
\hline Female & $83(32.7)$ & $41(47.7)$ \\
\hline Male & $171(67.3)$ & $45(52.3)$ \\
\hline \multicolumn{3}{|l|}{ Race, $n(\%)^{\mathrm{a}}$} \\
\hline Native American or alaska native & $2(0.8)$ & $0(0.0)$ \\
\hline Asian & $2(0.8)$ & $1(1.2)$ \\
\hline Black or African American & $14(5.5)$ & $4(4.7)$ \\
\hline Native Hawaiian or other Pacific Islander & $1(0.4)$ & $1(1.2)$ \\
\hline White & $227(89.7)$ & $80(93.0)$ \\
\hline Other & $7(2.8)$ & $0(0.0)$ \\
\hline BMI $\left(\mathrm{kg} / \mathrm{m}^{2}\right)$, mean $(\mathrm{SD})$ & $31.4(7.0)$ & $31.8(7.5)$ \\
\hline Duration of psoriasis (years), mean (SD) & $18.1(14.7)$ & $17.3(13.3)$ \\
\hline \multicolumn{3}{|l|}{ PGA, $n(\%)$} \\
\hline Moderate & $230(90.6)$ & $78(90.7)$ \\
\hline Severe & $24(9.5)$ & $8(9.3)$ \\
\hline BSA (\%), mean (SD) & $8.0(2.8)$ & $8.4(3.3)$ \\
\hline mPASI at baseline, mean (SD) & $8.4(4.0)$ & $8.2(3.6)$ \\
\hline \multicolumn{3}{|l|}{ PaGA at baseline, $n(\%)$} \\
\hline Very mild & $1(0.4)$ & $2(2.3)$ \\
\hline Mild & $44(17.3)$ & $15(17.4)$ \\
\hline Moderate & $159(62.6)$ & $57(66.3)$ \\
\hline Severe & $50(19.7)$ & $12(14.0)$ \\
\hline Itch score, mean $(S D)^{b}$ & $48.9(28.9)$ & $54.9(28.5)$ \\
\hline
\end{tabular}

$B M I$ body mass index, $B S A$ body surface area, Cal/BD foam fixed-dose combination calcipotriol/betamethasone dipropionate cutaneous foam, mPASI modified Psoriasis Area and Severity Index, PaGA patient's global assessment, PGA physician's global assessment, $S D$ standard deviation

a $\mathrm{Cal} / \mathrm{BD}$ group, $n=253$

b $\mathrm{Cal} / \mathrm{BD}$ group, $n=251$; foam vehicle group, $n=85$

\section{Efficacy}

\section{Treatment Success}

Treatment success by PGA at week 4 was achieved by $143(58.1 \%)$ and three (3.6\%) patients in the $\mathrm{Cal} / \mathrm{BD}$ foam and foam vehicle groups $(P<0.001)$, respectively (Fig. 1$)$. At week 1 , treatment success by PGA was achieved by 22 $(8.8 \%)$ and two $(2.4 \%)$ patients who received $\mathrm{Cal} / \mathrm{BD}$ foam and foam vehicle $(P=0.044)$, respectively. At week 2, treatment success by 


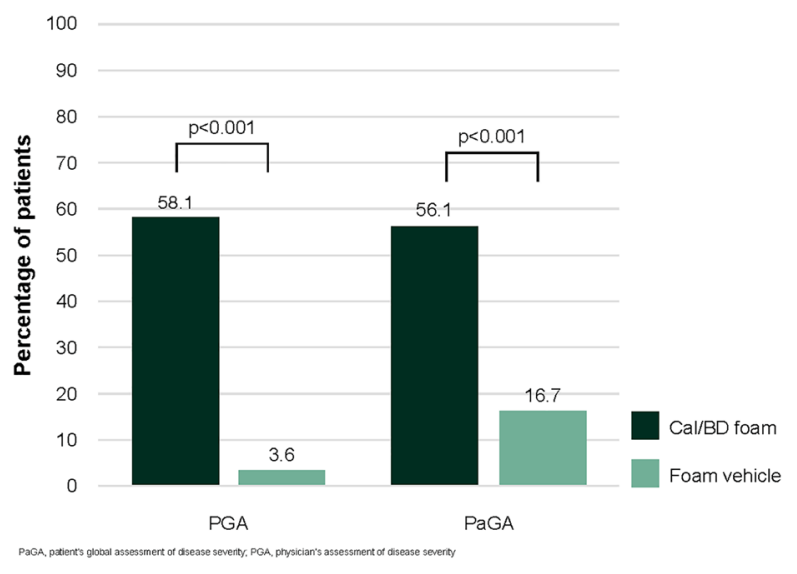

Fig. 1 Treatment success at week 4 by physician's global assessment $(P G A)$ and patient's global assessment $(\mathrm{PaGA})$ in the group treated with the fixed-dose combination calcipotriol/betamethasone dipropionate cutaneous foam (Cal/BD foam) and the group treated with vehicle (foam vehicle)

PGA was achieved by $72(28.8 \%)$ patients receiving $\mathrm{Cal} / \mathrm{BD}$ foam and two $(2.4 \%)$ patients receiving vehicle $(P<0.001)$.

Treatment success by PaGA at week 4 was achieved by 138 (56.1\%) and 14 (16.7\%) patients in the $\mathrm{Cal} / \mathrm{BD}$ foam and vehicle groups $(P<0.001)$, respectively (Fig. 1$)$.

\section{Other Efficacy Endpoints}

Mean itch scores decreased from a baseline of 48.9 (standard deviation [SD] 28.9) and 54.9 (SD 28.5) in the Cal/BD foam and foam vehicle groups, respectively, to 9.2 (SD 18.5) and 30.7 (SD 26.8) at week 4 (Fig. 2). Least squares (LS) mean itch values at week 4 were 10.0 and 30.8

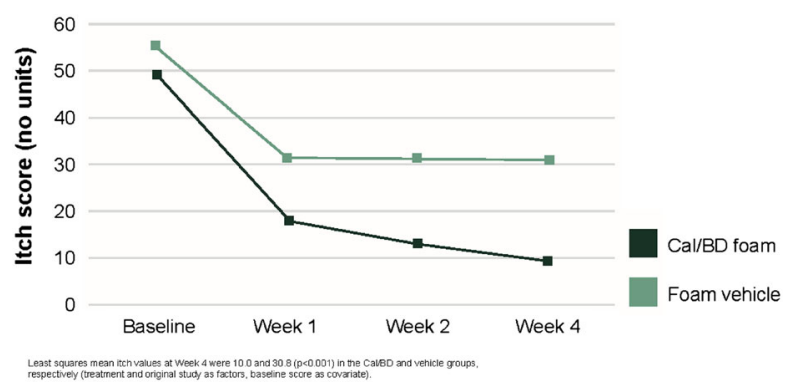

Fig. 2 Mean itch score in the Cal/BD foam and foam vehicle groups
$(P<0.001)$ in the $\mathrm{Cal} / \mathrm{BD}$ and vehicle groups, respectively.

By week 4, 136 (55.3\%) patients achieved PASI75 in the Cal/BD group compared with three $(3.6 \%)$ in the foam vehicle group $(P<0.001)$. Mean mPASI decreased from a baseline of 8.4 (SD 4.0) in the $\mathrm{Cal} / \mathrm{BD}$ foam group and 8.2 (SD 3.6) in the vehicle group, to 2.2 (SD 2.1) in the Cal/BD foam group and 5.8 (SD 2.7) in the foam vehicle group (Fig. 3). LS mean mPASI values at week 4 were 2.3 and 6.0 $(P<0.001)$ in the $\mathrm{Cal} / \mathrm{BD}$ and vehicle groups, respectively.

\section{Drug Usage}

Mean weekly amount of product used was $32.4 \mathrm{~g}$ (SD 20.5) and $35.8 \mathrm{~g}$ (SD 22.9) in the Cal/ $\mathrm{BD}$ foam and vehicle groups, respectively.

\section{Safety}

A total of 77 AEs was reported: 66 AEs in 47 (18.5\%) patients receiving Cal/BD foam versus 11 AEs in 11 (12.8\%) patients receiving foam vehicle $(P=0.25)$ (Table 2$)$. Ten $(3.9 \%)$ patients in the $\mathrm{Cal} / \mathrm{BD}$ foam group experienced 15 treatment-related AEs and two (2.3\%) patients in the foam vehicle group experienced two treatment-related AEs $(P=0.5)$. The most common treatment-related $\mathrm{AE}$ was pruritus (3 events in 3 patients in the Cal/BD group); all other treatment-related AEs were reported in no more than one patient each. Two (0.8\%) patients in the $\mathrm{Cal} / \mathrm{BD}$ foam group experienced three severe AEs, all of which were treatment related (application-site pruritus, pruritus and erythema), and no severe AEs were reported in the foam vehicle group. No serious AEs were reported in either group. AEs relating to steroid use that were reported by $>1$ patient were pruritus and folliculitis; these were experienced by three $(1.2 \%)$ and two $(0.8 \%)$ patients in the $\mathrm{Cal} / \mathrm{BD}$ group, respectively. All five of these patients had BSA $\leq 10 \%$ at baseline and applied a weekly average of between 6.3 and $55.7 \mathrm{~g}$ of Cal/BD foam. 


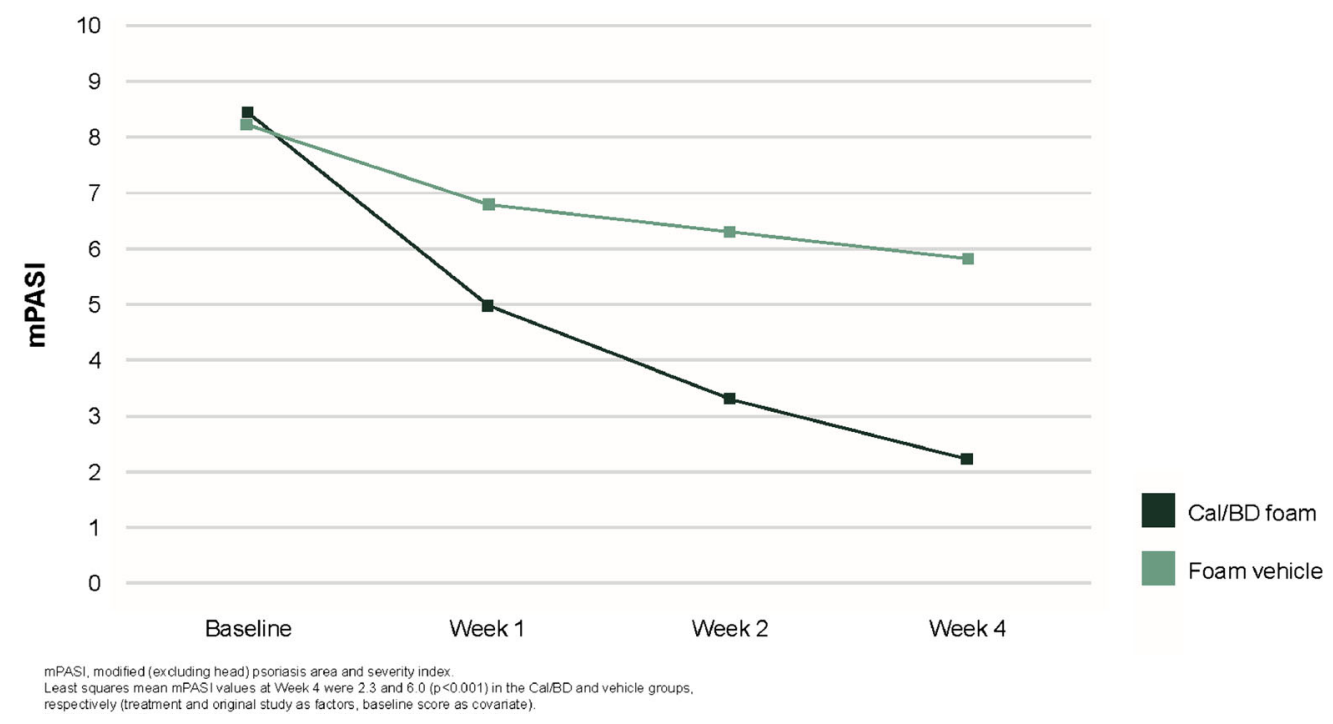

Fig. 3 Mean modified Psoriasis Area and Severity Index (mPASI) in the Cal/BD foam and foam vehicle groups

\section{DISCUSSION}

In this post-hoc subgroup analysis, patients with psoriasis vulgaris, with a BSA of $5-15 \%$ and a PGA of $\geq 3$, treated with Cal/BD foam showed significant improvements in assessments of disease severity at week 4 versus patients who received foam vehicle.

Patient perception of Cal/BD foam treatment success at week 4 was similar to that reported by the investigators $(56.1 \%$ by PaGA and $58.1 \%$ by PGA). Cal/BD foam treatment was generally well tolerated in this patient population, with a safety profile similar to that seen in the overall populations in each individual trial included in the analysis (patients with mild-to-severe psoriasis) [9-11].

This population was chosen to investigate whether Cal/BD foam could be a feasible treatment option for patients with at least moderate psoriasis; therefore, patients with psoriasis affecting $<5 \%$ BSA and a PGA of $<3$ were excluded. Patients with BSA $>15 \%$ were also excluded since it is not practically feasible or routinely recommended to treat this patient population using topical treatments alone $[1,4]$. Concerns over systemic absorption when using high topical-treatment doses have been raised [15]. In many cases of moderate-to-severe psoriasis treated with systemic therapies, complete clearance is not achieved, with residual and localized areas of psoriasis remaining [16]. Thus, Cal/BD foam is frequently used as an adjunct treatment to improve treatment outcomes when complete clearance is not achieved with systemic therapies alone.

In the Cal/BD group, two patients experienced folliculitis and three experienced pruritus (AEs relating to steroid use as determined by the investigator). These patients had a BSA $\leq 10 \%$ at baseline and applied a weekly average of between 6.3 and $55.7 \mathrm{~g}$ of Cal/BD foam (not exceeding the maximum dose as per the label [8]); thus, the AEs were probably caused solely by the topical application of Cal/BD foam and were not related to systemic absorption. Furthermore, in a recent clinical trial, maximal use of Cal/BD foam did not result in any effect on adrenal function and had no clinically relevant effect on calcium homeostasis [17].

Adherence to therapy is a major problem in patients with psoriasis, particularly for those with moderate-to-severe disease [18]. Patients with severe, widespread disease frequently lose confidence in the efficacy of a treatment, leading to non-adherence [19]. Time to improvement has therefore been highlighted as an important attribute of psoriasis treatments [20]. In the pooled analysis reported here, treatment success by PGA was achieved by 72 patients 
Table 2 Overview of adverse events according to treatment group

\begin{tabular}{|c|c|c|c|c|c|c|}
\hline \multirow[t]{2}{*}{ Event } & \multicolumn{3}{|c|}{ Cal/BD foam $(n=254)$} & \multicolumn{3}{|c|}{ Foam vehicle $(n=86)$} \\
\hline & $\begin{array}{l}\text { Number of } \\
\text { AEs }\end{array}$ & $\begin{array}{l}\text { Number of } \\
\text { patients }\end{array}$ & $\begin{array}{l}\% \text { of } \\
\text { patients }\end{array}$ & $\begin{array}{l}\text { Number of } \\
\text { AEs }\end{array}$ & $\begin{array}{l}\text { Number of } \\
\text { patients }\end{array}$ & $\begin{array}{l}\% \text { of } \\
\text { patients }\end{array}$ \\
\hline Total AEs & 66 & 47 & 18.5 & 11 & 11 & 12.8 \\
\hline Severe AEs & 3 & 2 & 0.8 & 0 & 0 & 0.0 \\
\hline Serious AEs & 0 & 0 & 0.0 & 0 & 0 & 0.0 \\
\hline Treatment-related AEs & 15 & 10 & 3.9 & 2 & 2 & 2.3 \\
\hline \multicolumn{7}{|c|}{ Treatment-related AEs by SOC and $\mathrm{PT}^{\mathrm{a}}$} \\
\hline $\begin{array}{l}\text { General disorders and } \\
\text { administration site conditions }\end{array}$ & 5 & 4 & 1.6 & 1 & 1 & 1.2 \\
\hline Application site pain & 2 & 1 & 0.4 & 0 & 0 & 0.0 \\
\hline Application site pruritus & 1 & 1 & 0.4 & 1 & 1 & 1.2 \\
\hline Application site discolouration & 1 & 1 & 0.4 & 0 & 0 & 0.0 \\
\hline Application site reaction & 1 & 1 & 0.4 & 0 & 0 & 0.0 \\
\hline $\begin{array}{l}\text { Skin and subcutaneous tissue } \\
\text { disorders }\end{array}$ & 6 & 4 & 1.6 & 1 & 1 & 1.2 \\
\hline Pruritus & 3 & 3 & 1.2 & 1 & 1 & 1.2 \\
\hline Blister & 1 & 1 & 0.4 & 0 & 0 & 0.0 \\
\hline Erythema & 1 & 1 & 0.4 & 0 & 0 & 0.0 \\
\hline Skin irritation & 1 & 1 & 0.4 & 0 & 0 & 0.0 \\
\hline Infections and infestations & 1 & 1 & 0.4 & 0 & 0 & 0.0 \\
\hline Folliculitis & 1 & 1 & 0.4 & 0 & 0 & 0.0 \\
\hline $\begin{array}{l}\text { Injury, poisoning and procedural } \\
\text { complications }\end{array}$ & 1 & 1 & 0.4 & 0 & 0 & 0.0 \\
\hline Burns, first-degree & 1 & 1 & 0.4 & 0 & 0 & 0.0 \\
\hline Investigations & 2 & 1 & 0.4 & 0 & 0 & 0.0 \\
\hline Blood calcium increased & 2 & 1 & 0.4 & 0 & 0 & 0.0 \\
\hline
\end{tabular}

$A E$ adverse events, $P T$ preferred term, $S O C$ system organ class

a Classification is according to MedDRA (Medical Dictionary for Regulatory Activities) version 15.1 (https://www.meddra. org/)

(28.8\%) as early as week 2 , compared with only $2(2.4 \%)$ patients in the foam vehicle group. Furthermore, an analysis of speed of action of $\mathrm{Cal} / \mathrm{BD}$ foam, performed on the overall population of these three trials, demonstrated a rapid onset of action with Cal/BD and a greater efficacy versus foam vehicle, even in patients with moderate-to-severe psoriasis [21]. These observations are consistent with increased skin penetration and local bioavailability associated with application of the stable, supersaturated Cal/BD foam [6].

Patients' perception of treatment success at week 4 (as evidenced by PaGA score), the 
reported improvements in itch and the tolerable safety profile all suggest the potential for improved treatment adherence in patients with moderate-to-severe psoriasis.

Adherence to topical treatments is higher in clinical trial settings than in everyday practice, which highlights one limitation of these pooled trials [22]; however, previous studies of $\mathrm{Cal} / \mathrm{BD}$ foam administered once daily have indicated that treatment success rates are also high in the real world in patients with psoriasis [12-14]. An additional limitation is that this was a post-hoc subgroup analysis based on pooled data from three trials, which were not initially designed to answer this particular research question. In addition, the majority of patients in this posthoc analysis were white, and so our findings may not be generalizable to all populations.

\section{CONCLUSION}

There are very few studies evaluating the use of topical treatments in patients with moderate-tosevere psoriasis. Therefore, this analysis of pooled data from three randomized, vehiclecontrolled trials adds valuable information supporting the use of $\mathrm{Cal} / \mathrm{BD}$ foam as an important potential treatment option for this patient population.

\section{ACKNOWLEDGEMENTS}

The authors would like to thank all of the patients who participated in the trials.

Funding. The trials (NCT01866163, NCT02132936, NCT01536886) and the journal's Rapid Service Fee were funded by LEO Pharma, Ballerup, Denmark.

Medical Writing Assistance. The authors would like to acknowledge Bridie Andrews, MSc, of iMed Comms, Macclesfield, UK, an Ashfield company, part of UDG Healthcare plc, for medical writing support that was funded by LEO Pharma in accordance with Good Publications Practice (GPP3) guidelines (https://www. ismpp.org/gpp3).
Authorship. All named authors meet the International Committee of Medical Journal Editors (ICMJE) criteria for authorship for this article, take responsibility for the integrity of the work as a whole, and have given their approval for this version to be published.

Prior Presentation. The data in this manuscript contains data from three pooled trials, each of which has been previously published individually [9-11] and presented at the 28th European Academy of Dermatology and Venereology (EADV) Congress, 9-13 October 2019, Madrid.

Disclosures. Lars Iversen has served as a consultant and/or paid speaker for and/or participated in clinical trials sponsored by AbbVie, Almirall, Amgen, AstraZeneca, Bristol-Myers Squibb, Boehringer Ingelheim, Celgene, Centocor, Eli Lilly, Janssen-Cilag, Kyowa, LEO Pharma, MSD, Novartis, Pfizer and UCB. Merle Kurvits and Anja M. Snel-Prentø are employees of LEO Pharma, Ballerup, Denmark. Alan Menter has served as a consultant and/or paid speaker for and/or participated in clinical trials and/or participated in advisory boards sponsored by Abbott Labs, Amgen, Boehringer Ingelheim, Celgene, Eli Lilly, Janssen Biotech Inc., LEO Pharma, Merck, Novartis, Sienna and UCB. Alan Menter is also a member of this journal's Editorial Board.

Compliance with Ethics Guidelines. Approval was obtained from all relevant Institutional Review Boards and/or Independent Ethics Committees and Regulatory Authorities prior to the enrollment of patients. All patients provided written informed consent. The trials were conducted in accordance with the Declaration of Helsinki 1964, as revised 2013, concerning human and animal rights, Good Clinical Practice and Ethical Principles for Medical Research Involving Human Subjects.

Data Availability. The datasets generated during and/or analyzed during the current study are available from LEO Pharma on reasonable request subject to approval of a Patient and Scientific Review Board. 
Open Access. This article is licensed under a Creative Commons Attribution-NonCommercial 4.0 International License, which permits any non-commercial use, sharing, adaptation, distribution and reproduction in any medium or format, as long as you give appropriate credit to the original author(s) and the source, provide a link to the Creative Commons licence, and indicate if changes were made. The images or other third party material in this article are included in the article's Creative Commons licence, unless indicated otherwise in a credit line to the material. If material is not included in the article's Creative Commons licence and your intended use is not permitted by statutory regulation or exceeds the permitted use, you will need to obtain permission directly from the copyright holder. To view a copy of this licence, visit http://creativecommons.org/licenses/by$\mathrm{nc} / 4.0 /$.

\section{REFERENCES}

1. Menter A, Korman NJ, Elmets CA, et al. Guidelines of care for the management of psoriasis and psoriatic arthritis. Section 3. Guidelines of care for the management and treatment of psoriasis with topical therapies. J Am Acad Dermatol. 2009;60:643-59.

2. Elmets CA, Leonardi CL, Davis DMR, et al. Joint AAD-NPF guidelines of care for the management and treatment of psoriasis with awareness and attention to comorbidities. J Am Acad Dermatol. 2019;80:1073-113.

3. Balato N, Napolitano M, Ayala F, et al. Nonalcoholic fatty liver disease, spleen and psoriasis: New aspects of low-grade chronic inflammation. World J Gastroenterol. 2015;21:6892-7.

4. Raychaudhuri SK, Maverakis E, Raychaudhuri SP. Diagnosis and classification of psoriasis. Autoimmunity Rev. 2014;13:490-5.

5. Menter A, Strober BE, Kaplan DH, et al. Joint AADNPF guidelines of care for the management and treatment of psoriasis with biologics. J Am Acad Dermatol. 2019;80:1029-72.

6. Lind M, Nielsen KT, Schefe LH, et al. Supersaturation of calcipotriene and betamethasone dipropionate in a novel aerosol foam formulation for topical treatment of psoriasis provides enhanced bioavailability of the active ingredients. Dermatol Ther. 2016;6:413-25.

7. Electronic medicines compendium (EMC). Enstilar cutaneous foam-summary of product characteristics. 2018. https://www.medicines.org.uk/emc/ product/2139. Accessed 6 Dec 2018.

8. US Food and Drug Administration. Enstilar-prescribing information. 2018. https://www. accessdata.fda.gov/drugsatfda_docs/label/2016/ 207589s001lbl.pdf. Accessed 6 Dec 2018.

9. Leonardi C, Bagel J, Yamauchi P, et al. Efficacy and safety of calcipotriene plus betamethasone dipropionate aerosol foam in patients with psoriasis vulgaris-a randomized phase III study (PSO-FAST). J Drugs Dermatol. 2015;14:1468-77.

10. Paul C, Stein Gold L, Cambazard F, et al. Calcipotriol plus betamethasone dipropionate aerosol foam provides superior efficacy vs. gel in patients with psoriasis vulgaris: randomized, controlled PSO-ABLE study. J Eur Acad Dermatol Venereol. 2017;31:119-26.

11. Koo J, Tyring S, Werschler WP, et al. Superior efficacy of calcipotriene and betamethasone dipropionate aerosol foam versus ointment in patients with psoriasis vulgaris-a randomized phase II study. J Dermatolog Treat. 2016;27:120-7.

12. Pinter A, Thormann H, Angeletti F, Jalili A. Calcipotriol/betamethasone dipropionate aerosol foam for the treatment of psoriasis vulgaris: case series and review of the literature. Clin Cosmet Investig Dermatol. 2018;11:451-9.

13. Gerdes S, Krakor M, Anger T, Hutt HJ, Korber A. Prospective, observational, non-interventional, multicentre study on the efficacy and tolerability of a new calcipotriol/betamethasone aerosol foam (Enstilar®) in patients with plaque psoriasis under daily practice conditions. Dermatology. 2017;233: 425-34.

14. Gallo L, Megna M, Cirillo T, et al. Psoriasis and skin pain: real-life effectiveness of calcipotriol plus betamethasone dipropionate in aerosol foam formulation. J Eur Acad Dermatol Venereol. 2019;33: 1312-5.

15. Torsekar R, Gautam MM. Topical therapies in psoriasis. Indian Dermatol Online J. 2017;8:235-45.

16. Hjuler KF, Iversen L, Rasmussen MK, Kofoed K, Skov $\mathrm{L}$, Zachariae C. Localization of treatment-resistant areas in patients with psoriasis on biologics. Br J Dermatol. 2019;181:332-7.

17. Taraska V, Tuppal R, Olesen M, Bang Pedersen C, Papp K. A novel aerosol foam formulation of 
calcipotriol and betamethasone has no impact on HPA axis and calcium homeostasis in patients with extensive psoriasis vulgaris. J Cutan Med Surg. 2016;20:44-51.

18. Bewley A, Page B. Maximizing patient adherence for optimal outcomes in psoriasis. J Eur Acad Dermatol Venereol. 2011;25(Suppl 4):9-14.

19. Zaghloul SS, Goodfield MJ. Objective assessment of compliance with psoriasis treatment. Arch Dermatol. 2004;140:408-14.

20. Seston EM, Ashcroft DM, Griffiths CE. Balancing the benefits and risks of drug treatment: a stated- preference, discrete choice experiment with patients with psoriasis. Arch Dermatol. 2007;143: 1175-9.

21. Pink AE, Jalili A, Berg P, et al. Rapid onset of action of calcipotriol/betamethasone dipropionate cutaneous foam in psoriasis, even in patients with more severe disease. J Eur Acad Dermatol Venereol. 2019;33:1116-23.

22. Devaux S, Castela A, Archier E, et al. Adherence to topical treatment in psoriasis: a systematic literature review. J Eur Acad Dermatol Venereol. 2012;26(Suppl 3):61-7. 